\title{
Intensive shipboard observations of the flow through the Strait of Gibraltar
}

\author{
Uwe Send and Burkard Baschek ${ }^{1}$ \\ Institut für Meereskunde, Kiel, Germany
}

\begin{abstract}
During the European project Canary Island Azores Gibraltar Experiment (CANIGO), intensive shipboard observations were carried out in April 1996 and October 1997 in order to observe the spatial and temporal variability of the flow and of the water mass structure in the Strait of Gibraltar. At the sill and the eastern and western entrances to the strait, repeated cross-strait sections and station time series of the flow and of $T-S$ profiles were measured using vessel-mounted and lowered acoustic Doppler current profilers (ADCP) and conductivity-temperature-depth probes (CTD)/expendable bathythermographs (XBT), yielding new views of the rapid changes over tidal cycles and of approximate tidal means. It is argued that transport observations might be easier to carry out away from the sill, in the eastern part of the strait, even though maximum resolved shears were comparable in both places, $0.03-0.04 \mathrm{~s}^{-1}$ in the vertical and 0.001$0.016 \mathrm{~s}^{-1}$ in the horizontal. In the east, coordinated changes in the stratification and the flow field are documented via four time series over $M_{2}$ tidal cycles, showing a sharpening/ diffusing of the vertical gradients in the water masses and the flow. Maximum shear and maximum water mass gradients do not always coincide there, and both are much shallower $(50-80 \mathrm{~m})$ than the delimiter between inflow and outflow $(120-150 \mathrm{~m})$. The mean salinity of the outflow core decreases from 38.43 in the east to 38.17 west of the sills as a result of the mixing processes. The internal bore was followed and directly observed with rapid CTD-yoyo stations and with XBT/vessel-mounted ADCP measurements. It generates extreme changes in currents and shears on timescales of minutes, with directly measured vertical velocities reaching $\pm 50 \mathrm{~cm} \mathrm{~s}^{-1}$. Patches of density inversions were observed as the bore passed by, consistent with active turbulent mixing along the interface. The time series of flow and CTD measurements allow the direct calculation of Froude numbers at various locations and over tidal cycles. These and along-strait sections suggest that the exchange through the strait is maximal in April 1996 and submaximal in October 1997, supporting the expectations of Garrett et al. [1990].
\end{abstract}

\section{Introduction}

The Strait of Gibraltar is a choke point in the exchange between the Atlantic Ocean and the Mediterranean Sea. Accurate observations of the mass, salt, and heat transports there provide important integral information about the processes in the interior of the basin. Time variability in these transports may be indicative of changes in the strait dynamics or in the basin interior balances. In future forecasting systems, accurate observations of the exchange flow and of the water mass properties may also serve to provide boundary conditions or constraints for numerical models.

The Strait of Gibraltar is a complicated environment, both dynamically and logistically. Huge changing currents, large horizontal and vertical shears, a strong and nonlinear tidal regime, internal bores, and hydraulic processes contribute to the difficulty in studying this area. Partly because of this adverse environment (including also corrosion) and probably

\footnotetext{
${ }^{1}$ Now at Institute of Ocean Sciences, Sidney, British Columbia, Canada.

Copyright 2001 by the American Geophysical Union.

Paper number 2000JC000459.

0148-0227/01/2000JC000459\$09.00
}

partly because of human interference (fishing, etc.), moorings are frequently lost or get damaged. The highway-like shipping through the strait makes oceanographic work difficult as well. In spite of this, there have been a number of studies in the past, some using shipboard measurements [Armi and Farmer, 1988; Farmer and Armi, 1988; Bray et al., 1995] and several using moored equipment [Candela, 1991; Bryden et al., 1994]. The moorings generally only sample at a few points across the strait, while ship observations lack the temporal information on how observed structures may change with time (especially in this tidally dominated regime).

The observations presented here are part of an effort to merge high spatial resolution from ship observations with good temporal data from various moorings in the strait. The two cruises Poseidon 217 and 234 (in spring and in fall, respectively) used traditional nonsynoptic conductivity-temperaturedepth (CTD)/lowered acoustic Doppler current profiler (LACP) sections, rapid quasi-synoptic vessel-mounted ADCP (vmADCP) repeat sections (many repeats over full tidal cycles), CTD/LADCP time series stations at one place over one or more complete tidal cycles, and dedicated observations of the internal bore. In this paper the shipboard observations are presented, emphasizing the distributions and variability of flow and water masses on several sections across the strait and estimating the hydraulic state of the strait. A companion paper 


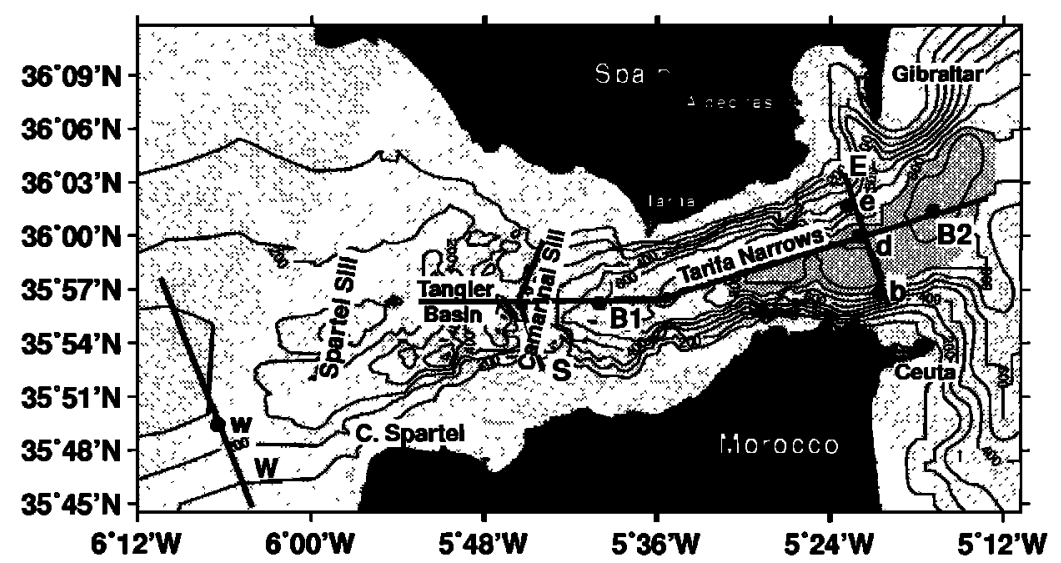

Figure 1. The bathymetry of the Strait of Gibraltar. Sections occupied with vessel-mounted ADCP and/or CTD probes are shown by the black lines (E, eastern section; $S$, sill section; $W$, western section). The location of CTD time series measurements used here (b, d, e, and w) and the locations of the bore measurements (B1 and $B 2$ ) are marked by dots.

[Baschek et al., this issue] (hereinafter referred to as BSLC) merges the spatial information from the data presented here with moored time series from extended periods at the eastern entrance of the strait, in order to yield improved estimates of the exchange volume transports.

\section{Measurement Techniques}

The intensive shipboard observations were carried out with CTD, XBT, vmADCP, and IADCP in order to obtain a good picture of the spatial structure and the variability of the flow through the Strait of Gibraltar.

A $150-\mathrm{kHz}$ lowered ADCP, which was mounted on the frame of the CTD rosette, was used to measure current profiles extending nearly to the bottom of the strait. The profiles were corrected for ship drift, using the data from a GPS/GLONASS receiver. Because of the partly extreme currents and nautical constraints in the busy Strait of Gibraltar, a large wire angle and tilt of the 1ADCP could not always be avoided. The data with a tilt of the instrument of more than $17^{\circ}$ were not used.

The underway measurements of the current were carried out with a $150-\mathrm{kHz}$ vessel-mounted ADCP with a beam angle of $30^{\circ}$. For navigation a GLONASS/GPS receiver was used, and the ship's heading was determined with a gyrocompass. The temporal resolution (ensemble length) was 120 or $180 \mathrm{~s}$, and the vertical resolution (bin length) was $16 \mathrm{~m}$. The vertical range of the ADCP was typically $400 \mathrm{~m}$, so that the currents of the upper layer, of the interface layer, and of the upper part of the lower layer could be measured. As always with this technique, there are gaps near the surface (upper $25 \mathrm{~m}$ ) and in the 30-50 $\mathrm{m}$ above the bottom.

At the eastern entrance of the strait ( $E$ in Figure 1), at the Camarinal Sill (S), and west of Spartel Sill (W), the vmADCP was used for a set of rapid quasi-synoptic cross-strait sections over approximately one full $M_{2}$ tidal cycle each. During these sections the ship steamed as fast as possible with a speed of $\sim 12$ knots, taking typically 50 min for one crossing. When the ship turned and headed back again the gyrocompass oscillated owing to the acceleration of the ship (Schuler oscillations [Schuler, 1923]). A correction of this error was not possible for the measurements of the cruise Poseidon 217 but was applied for the cruise Poseidon 234 with the help of a three- dimensional (3-D) Ashtec GPS system. In addition, the data were corrected for transducer orientation.

Conductivity, temperature, and pressure were measured at various locations in the strait with a Neil Brown Mk3 CTD system. It was calibrated using bottle samples and reversing thermometers. The CTD was used in two different modes. One consisted of single full-depth casts at several locations along a section or of full-depth repeat stations at a given location over a full $M_{2}$ tidal cycle. This was done to measure the temporal changes of the hydrographic structure and was usually combined with simultaneous IADCP and vmADCP measurements. Normally, the whole water column was thus covered with CTD and ADCP data, and water samples were taken for calibration.

In the other mode the CTD was used at a given location for continuous rapid up and down casts ("CTD-yoyo") in the upper $300 \mathrm{~m}$ of the water column. Each round-trip profile took $\sim 10 \mathrm{~min}$. The goal of these measurements was to get a view of the temporal changes of the water mass characteristics and of the depth of the interface between Atlantic and Mediterranean water as the internal bore passes by. At the same time the vmADCP was running to investigate the corresponding distributions of the 3-D currents.

For rapid underway sampling of the water mass structure and in support of vmADCP measurements, T- 6 XBTs with a maximal range of $460 \mathrm{~m}$ were used during Poseidon 234. They were complemented by CTD data where possible.

\section{Observations}

\subsection{Camarinal Sill (Section $\mathrm{S}$ )}

Camarinal Sill is the traditional location where most observations of the flow through the strait have been carried out in the past. Its typical depth in the center is $300-350 \mathrm{~m}$, and the width (between the $50-\mathrm{m}$ isobaths) is only $10 \mathrm{~km}$. Owing to the constriction, the flows and shears are very large. Plate 1 shows every second transect of a sequence of rapid vmADCP sections across the strait at this location. Each crossing takes $\sim 50 \mathrm{~min}$, thus the time difference between the shown sections is $\sim 2$ hours. The single sections are not strictly synoptic in view of the large tidal variability. The variability is dominated by nearbarotropic tidal currents [Candela, 1991], but there is also a large amount of small-scale structure. The typical currents 

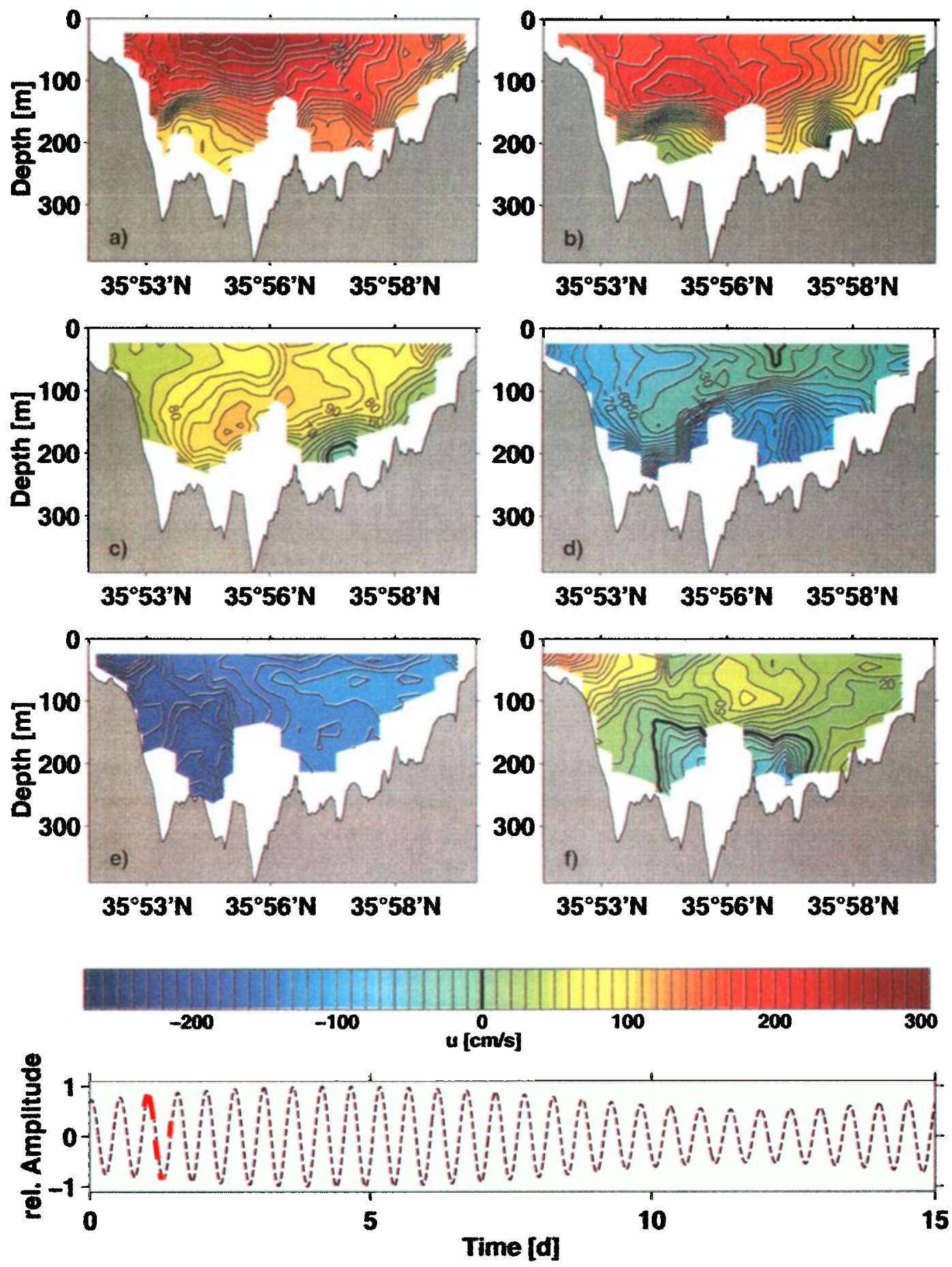

Plate 1. Measurements of the along-strait current $\left(\mathrm{cm} \mathrm{s}^{-1}\right)$ with a vmADCP at Camarinal Sill (S) during different parts of a $M_{2}$ tidal cycle (Poseidon 234). Every second transect is shown. The time difference between the single sections is $\sim 2$ hours. Contour interval is $10 \mathrm{~cm} \mathrm{~s}^{-1}$. The bottom panel shows the times of the sections during the tidal flow cycle.

range from -150 to $250 \mathrm{~cm} \mathrm{~s}^{-1}$ and from -200 to $100 \mathrm{~cm} \mathrm{~s}^{-1}$ in the upper and lower layers, respectively, with resolved shears up to $0.041 \mathrm{~s}^{-1}$ in the vertical and up to $1.6 \times 10^{-3} \mathrm{~s}^{-1}$ in the horizontal. We have one such $M_{2}$ sequence of sections from spring 1996 and one from fall 1997. The average formed over these approximate tidal periods ( 12 sections) is shown for the fall case in Plate 2. Even though the mean interface is reasonably smooth and well defined, it should be kept in mind that for transport calculations its motion due to tidal variability ( $\pm 100 \mathrm{~m}=2 \mathrm{rms}$ ) needs to be followed and correlated with the velocity fields shown in Plate 1 , which accounts for roughly half of the total transport there [Bryden et al., 1994].

\subsection{Eastern Section (E)}

The prior mooring studies at the sill have shown that it is difficult to follow the interface motion over the cross section 


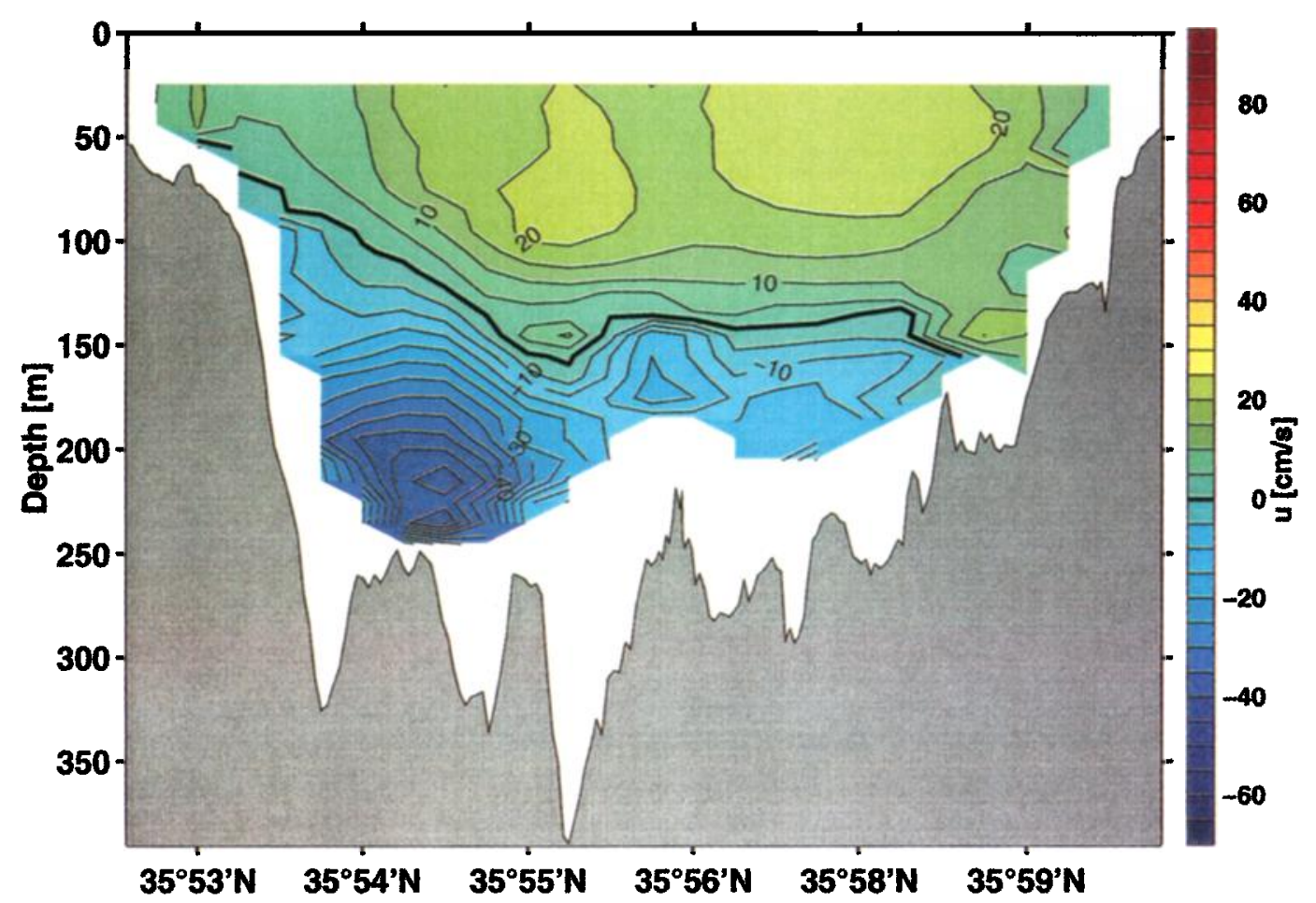

Plate 2. Approximate tidal-mean along-strait current $\left(\mathrm{cm} \mathrm{s}^{-1}\right)$ through the Strait of Gibraltar at Camarinal Sill from vmADCP sections from Poseidon 234.

there (strictly this requires several moorings with salinity sensors throughout the water column, which is a challenge in the presence of large mooring subduction due to currents). It is also difficult to extend the measurements of the highly sheared flows from a midwater ADCP or point sampling to the surface (and bottom). Therefore places other than Camarinal Sill might be more convenient for observing the flow through the strait. One such location is suggested to be farther east in the strait, along the line marked $E$ in Figure 1. There the interface moves only about $\pm 30 \mathrm{~m}$ vertically over a tidal cycle, and tidal currents are less extreme, which gives an expected tidally rectified transport contribution of only $7 \%$ (BSLC). Also, the lower layer is so deep $(700-800 \mathrm{~m})$ along this section that low-frequency or mean interface changes do not significantly affect transport estimates. For this reason and because of the suitability for acoustic measurements carried out there at the same time [Send et al., 2001], the eastern line (E) was intensively observed during the cruises. Plate 3 shows a sequence of quasi-synoptic flow sections at this site, over the depth range covered by the vmADCP. The typical currents here $(+20$ to $+100 \mathrm{~cm} \mathrm{~s}^{-1}$ and -80 to $+40 \mathrm{~cm} \mathrm{~s}^{-1}$ for upper/lower layers) are not as extreme as those at the sill, but the resolved shears are comparable (up to $0.034 \mathrm{~s}^{-1}$ in the vertical and $9.3 \times 10^{-4}$ $\mathrm{s}^{-1}$ in the horizontal).

One sequence of vmADCP sections over a tidal cycle is available from spring, and one is available from fall. While there are differences between these two tidal averages, here we show only the total average from both seasons (Plate 4). The seasonal changes in interface depth (based on salinity) will later be emphasized in Figure 7. Note that the flow distribution shown in the average of Plate 4 may still be biased by lowfrequency fluctuations, which may have amplitudes of $\pm 10 \mathrm{~cm}$ $\mathbf{s}^{-1}$ and which would thus shift the zero-current line vertically by some $20 \mathrm{~m}$. Shown in Plate 4 is also the typical position of two isohalines on this section (average of four nonsynoptic CTD sections). The shallower one is the $\mathbf{3 7 . 0}$ isohaline, which Bryden et al. [1994] used as the delimiter between inflow and outflow layers at the sill. The other is the 38.1 isohaline, which is chosen in the companion paper BSLC to represent the boundary between inflow and outflow at this eastern section $\mathrm{E}$. The superposition shows that these inflow/outflow layers are not defined by the interface (i.e., maximum vertical gradients, $\sim 50-80 \mathrm{~m}$ depth) and that the definition from the sill is not appropriate in the east.

The full lower layer could only be observed with CTD/ 1ADCP casts, making synoptic sections impossible. Instead, time series stations were occupied at three sites across this section (b, d, and e in Figure 1), cycling the CTD and ADCP up/down 12-17 times per $M_{2}$ tidal cycle. While this does not allow us to fill the gaps in the section shown in Plate 4 directly (but via the inverse model in the companion paper), these data give information on the depth-time evolution at a point. Plate 5 shows a color contour presentation of the flow, with isohalines superimposed as lines, for the four tidal cycles (noncontiguous) we observed in the center of the eastern section (near point d, Figure 1). The first and the last series were taken near neap tide, the third one was taken near spring tide. The tidal excursion of the isohalines and the correspondence with the flow field are clearly visible. As already noted by Bray et al. [1995], the interface is not a coherent single layer but may split into several gradient regions. Plate 6 shows the vertical shear of the flow, with the same isohalines as before. The shear layer is generally found in regions of high water mass (and density) gradients and translates in concert with the isohalines, but the location of maximum shear does not always coincide with the same isohalines. 

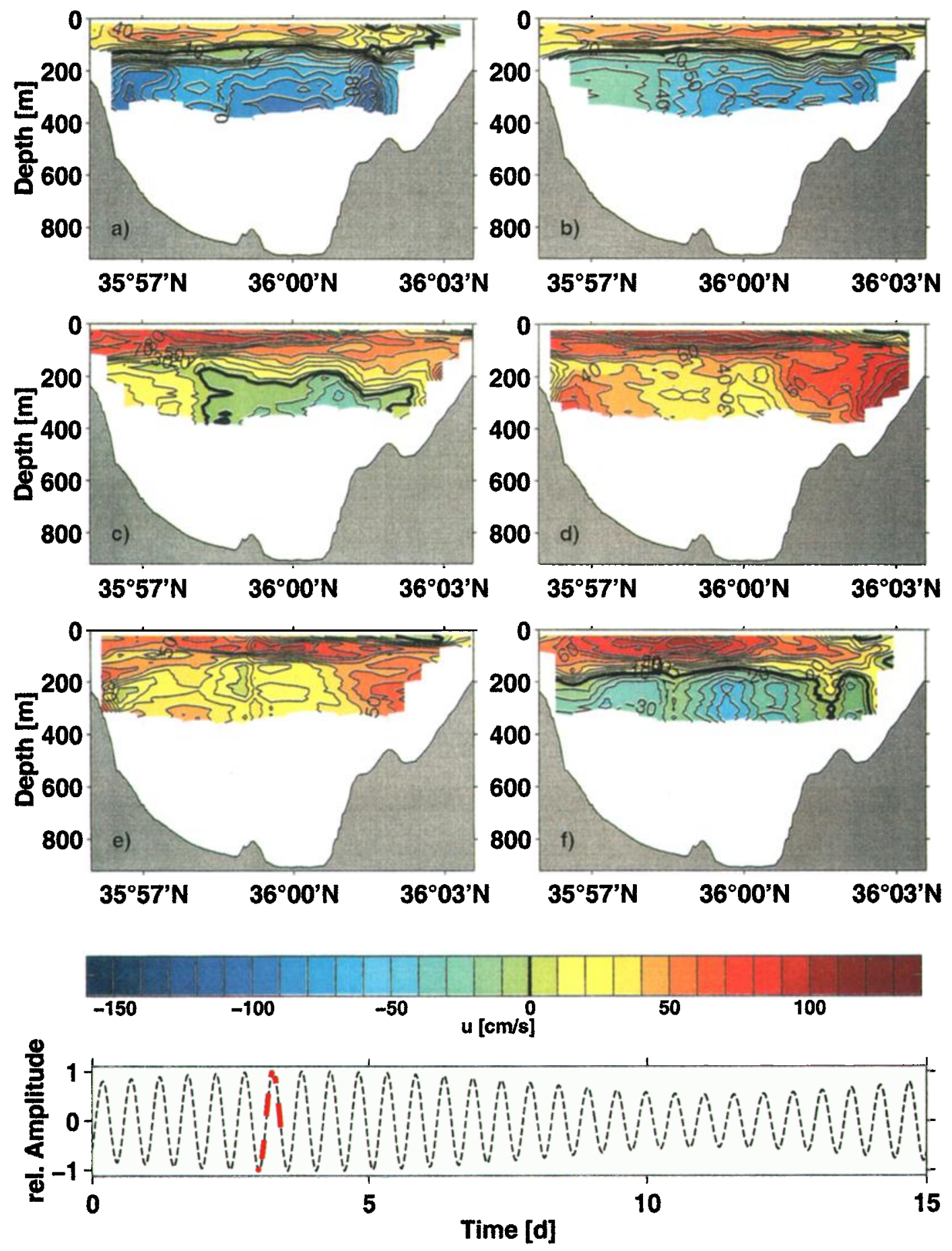

Plate 3. Measurements of the along-strait current $\left(\mathrm{cm} \mathrm{s}^{-1}\right)$ with a vmADCP at the eastern entrance of the Strait of Gibraltar (E) during different parts of a $M_{2}$ tidal cycle (Poseidon 234). Every second transect is shown. The time difference between the single sections is $\sim 2$ hours. Contour interval is $10 \mathrm{~cm} \mathrm{~s}^{-1}$. Bottom panel is as in Plate 1.

A summary plot of the tidal variability observed via time series stations at three locations across the eastern section (sites b, d, and c in Figure 1) is given in Plate 7. For temperature and salinity it shows the mean profiles and the rms vertical excursions over the tidal cycles observed. Note that the vertical extent of the gradient layers does not arise significantly from the vertical excursions of the interface while averaging in depth coordinates. The averaging was also attempted in salin- ity coordinates relative to the interface depth (different isohalines were tested), with no noticeably different results. In velocity the variability arises from the tidal oscillations; therefore the mean profiles in this case are overlaid with horizontal bars indicating the rms changes. Note that even though the $S, T$, and flow profiles show approximate $M_{2}$ tidal means, the flow may be shifted and distorted by low-frequency variability.

The mean salinity and temperature profiles at the southern 


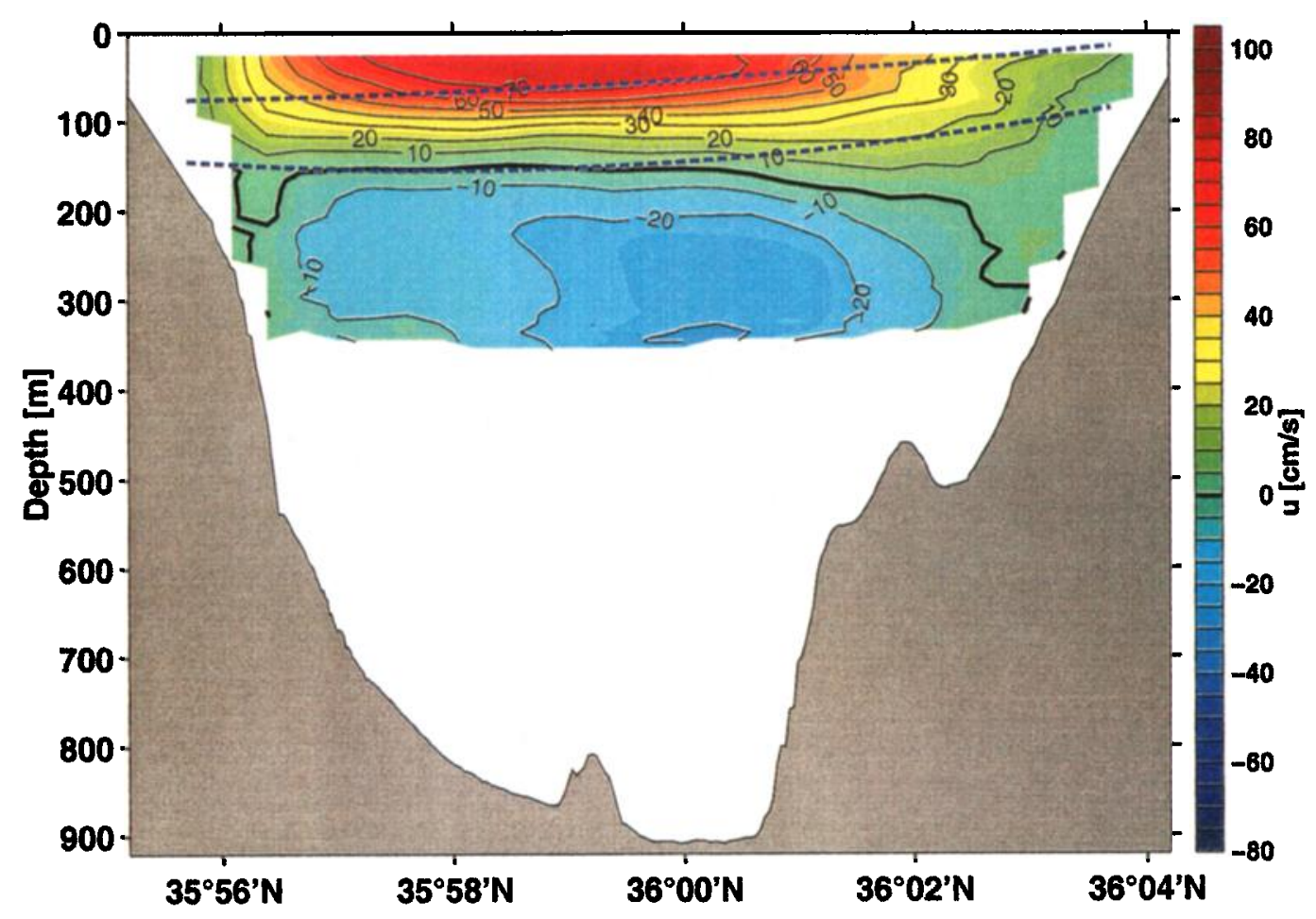

Plate 4. Approximate tidal-mean along-strait current $\left(\mathrm{cm} \mathrm{s}^{-1}\right)$ through the eastern entrance of the Strait of Gibraltar from vmADCP sections from Poseidon 217 and Poseidon 234. The 37.0 (upper) and 38.1 (lower) isohalines are shown as dashed lines.

station $b$ (Plate 7) have a much lower interface than the stations $\mathrm{d}$ and $\mathrm{e}$, caused by rotational effects. Probably owing to boundary effects, the interface at this station $b$ is also much broader, which is also indicated by some of our vmADCP sections (as in Plate 4). Sometimes the zero-flow contour dips downward near the side boundaries, leading to inflow in layers below $200 \mathrm{~m}$. To clarify to overall salinity structure on this section, Plate 8 shows a mean of four CTD sections at this place. This is still subject to tidal aliasing, since each section took $\sim 6$ hours to complete, but for guidance the magnitude of this variability can be assessed from Plate 7 .

\subsection{Western Section (W)}

In order to obtain equivalent views of the flow and water mass properties after the Mediterranean water passes the sills and the hydraulic jump there, one $M_{2}$ tidal sequence of transects was carried out at a site west of Spartel Sill (section W, Figure 1) during spring tide. Plate 9 shows the average of those eight vmADCP sections, and Figure 2 contains summary plots of the corresponding average water mass structure (from eight CTD casts) near the deepest part of the section. The Mediterranean water layer has descended with the bathymetry, approximately preserving its thickness compared to Camarinal Sill [Bryden et al., 1994]. The rms tidal excursions in the vertical are still significant, while the flow amplitudes have decreased somewhat. An interesting comparison results from merging the salinity profiles obtained at the east, near the sill, and at this western section. Plate 10 plots all these together, with the western profile also offset upward for comparison. It is apparent that the gradient layer with salinities from $\sim 36.5$ to 38.0 does not change much from the east to the west. The break below the gradient layer occurs in all cases at around 38.0; therefore the layer below 38.0 might be regarded as the core of the Mediterranean water. This is consistent with measurements from Price et al. [1993] and with the flow observations, which show that this layer is always within the depths of mean outflow. Averaged over this layer (depth of $S=38$ to bottom), a steady decrease of salinity can be observed from east to west, which must be a result of the mixing in the strait. The salinity changes from 38.43 at section $\mathrm{E}$, to 38.42 at station $\mathrm{B} 1$, to 38.14 at section W, also in agreement with Price et al. [1993].

\subsection{Internal Bore}

Another set of intensive observations was dedicated to the internal bore, which is released at the Camarinal Sill when the outflowing tide weakens and the water is pushed from the Atlantic back into the Strait of Gibraltar. The measurements of the internal bore at various locations in the strait with rapid CTD-yoyos and vmADCP data allowed us to observe the evolution of the bore while it propagates toward the east into the Mediterranean Sea. It is a dominant but very short-lived feature, and it is not clear for which larger-scale processes or integral properties it plays an important role. The original motivation for our observations was to use such data to predict its effect on cross-strait acoustic transmissions. All measurements were corrected for ship drift, assuming a constant propagation speed of the bore of $2.1 \mathrm{~m} \mathrm{~s}^{-1}$.

The first measurement was carried out very close to Camarinal Sill (B1, Plate 11). Before the signal of the bore reaches the location of measurement, the current has nearly no vertical shear. Vertical velocities are negligible, and the 37.4 isohaline, which roughly represents the location of the interface between Atlantic and Mediterranean water at the sill, lies in $\sim 30 \mathrm{~m}$ depth. The arrival of the bore is indicated by a sudden lowering 

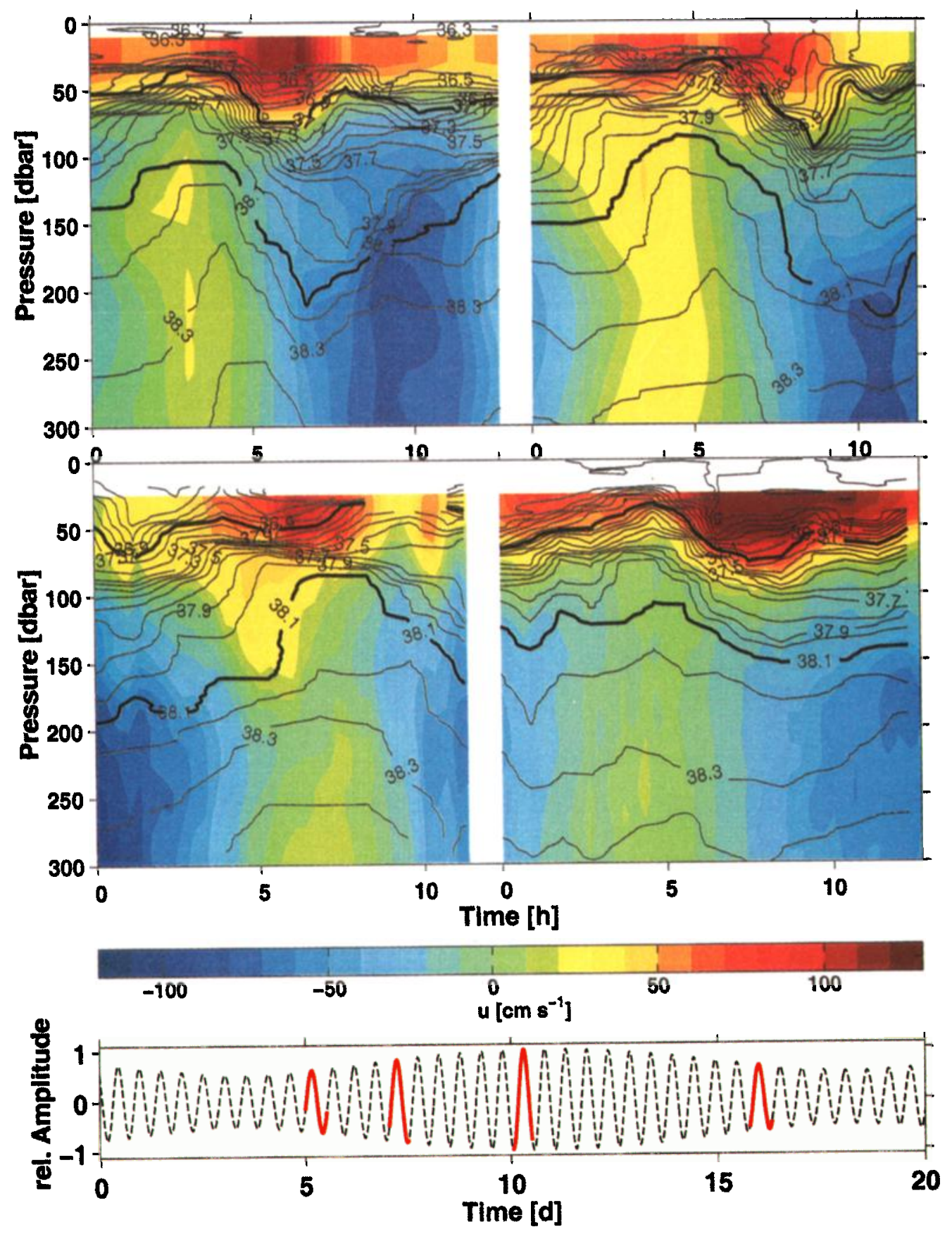

Plate 5. Four time series over tidal cycles of along-strait lADCP/vmADCP currents $\left(\mathrm{cm} \mathrm{s}^{-1}\right)$ at the center of the eastern section, site $d$ (colored), with isohalines from CTD measurements superimposed (black lines). Heavy lines are the 37.0 and 38.1 isohalines. Bottom panel is as in Plate 1.

of the interface by $\sim 150 \mathrm{~m}$. This is accompanied by a strong increase of the vertical shear (values up to $0.035 \mathrm{~s}^{-1}$ were observed) with currents in the upper layer of up to $150 \mathrm{~cm} \mathrm{~s}^{-1}$ and in the lower layer of up to $-80 \mathrm{~cm} \mathrm{~s}^{-1}$. All this happens within minutes and is associated with extreme vertical currents reaching values of $\pm 50 \mathrm{~cm} \mathrm{~s}^{-1}$. The Richardson number was estimated according to

$$
R i=\frac{g d \rho / d z}{\rho_{0}(d u / d z)^{2}},
$$

with the density $\rho$, the current speed $u$, and the depth coordinate $z$. It reveals regions where the density was unstably strat- ified (Plate 11, bottom). The more extreme inversions can be associated with salinity anomalies that have detached from the interface. There are some suggestions that after the bore has passed, patches of unstratified/unstable water may be left behind.

This bore was followed to the east and was measured again close to the eastern entrance of the strait (Plate 12). The change in the horizontal velocities of the upper and lower layer was smaller than that at the sill, reaching flows of +70 and -40 $\mathrm{cm} \mathrm{s}^{-1}$, respectively. Also, the vertical current $\left( \pm 20 \mathrm{~cm} \mathrm{~s}^{-1}\right)$ and the vertical excursions of the interface $(70 \mathrm{~m})$ were significantly smaller in the east. On the other hand, the signals of the bore were present over a longer period of time in the east, 

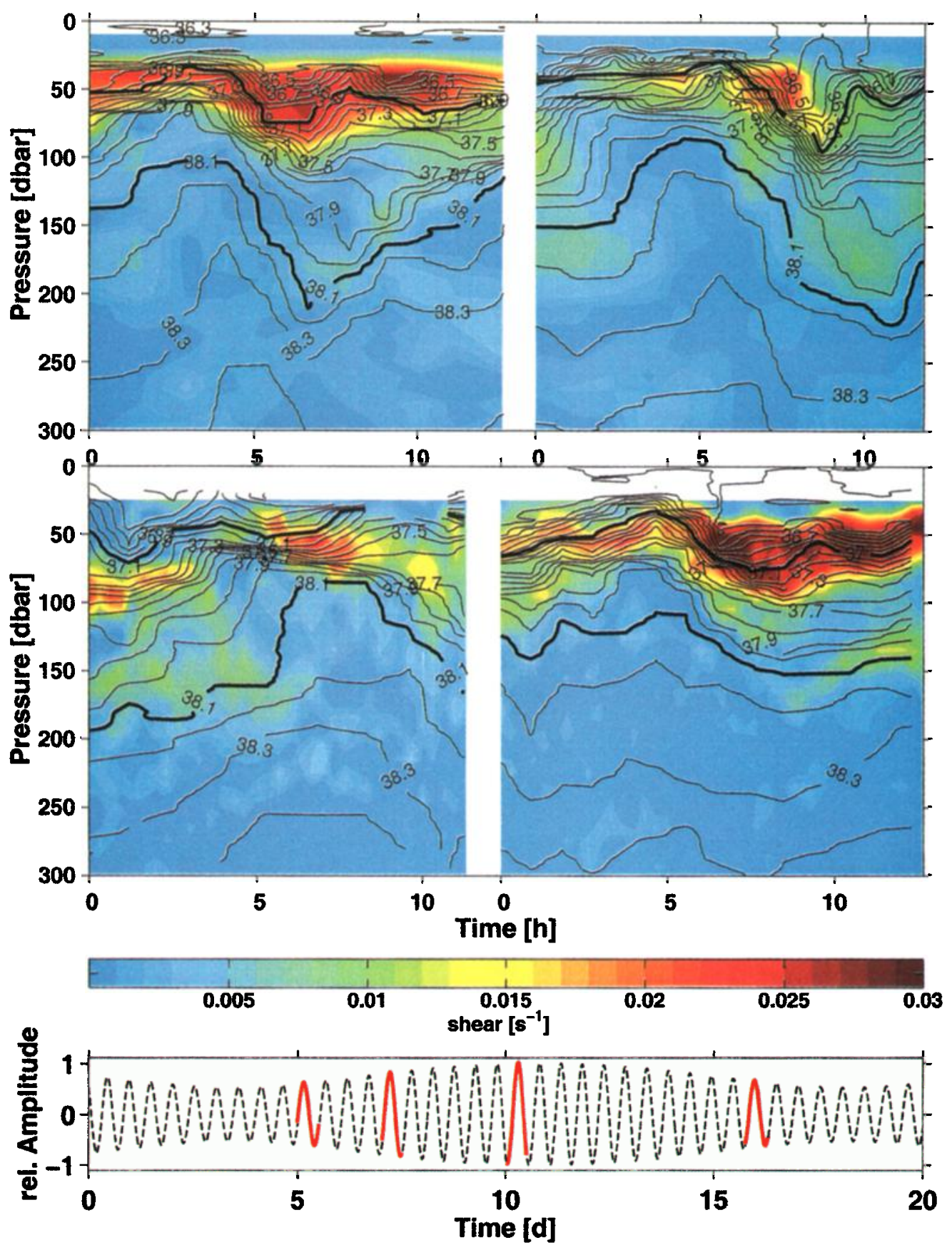

Plate 6. Four time series over tidal cycles of the vertical shear of along-strait $1 A D C P / v m A D C P$ currents $\left(\mathrm{s}^{-1}\right)$ at the center of the eastern section, site $\mathrm{d}$ (colored), with isohalines from CTD measurements superimposed (black lines). Heavy lines are the 37.0 and 38.1 isohalines.

showing the dispersion of the wave packet during its propagation.

\section{Froude Numbers}

Ideally, the Strait of Gibraltar can be described as a twolayer system (Figure 3). According to the theory of hydraulic control, the flow through the strait is controlled and the exchange is maximal when the flow east of the contraction and west of the sill is supercritical [e.g., Armi and Farmer, 1986; Farmer and Armi, 1986]. There the composite Froude number

$$
G^{2}=F_{1}^{2}+F_{2}^{2}, \quad F_{\imath}^{2}=\frac{u_{\imath}^{2}}{\left(1-\rho_{1} / \rho_{2}\right) g h_{\imath}},
$$

has values of $G^{2}>1$, with $u_{i}$ being the current, $\rho_{l}$ being the density, and $h_{\imath}$ being the thickness of layer $i$, with the indices $i=1$ for the upper layer and $i=2$ for the lower layer. Assuming that the flow west of the sill is supercritical most of the time, the condition $G^{2}>1$ in the east results for maximal exchange.

An estimation of $G^{2}$ from measurements is not straightforward, since the theory which leads to the condition $G^{2}=1$ for 


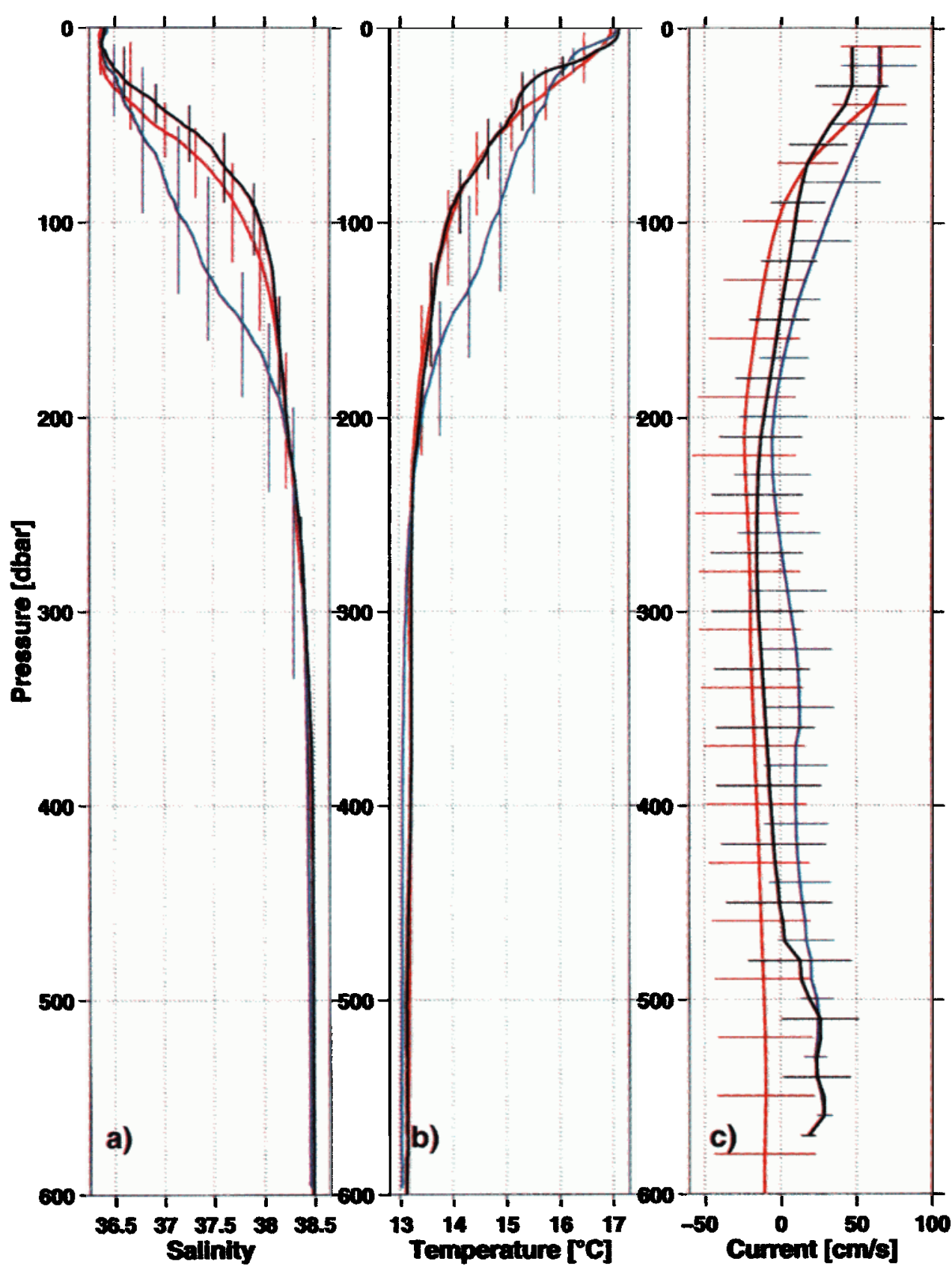

Plate 7. Mean profiles of (a) salinity, (b) temperature $\left({ }^{\circ} \mathrm{C}\right)$, and (c) along-strait current $\left(\mathrm{cm} \mathrm{s}^{-1}\right)$, measured at station $\mathrm{b}$ (blue; spring tide), station $\mathrm{d}$ (red; mean of two tidal cycles at neap tide, one at spring tide), and station e (black; spring tide) at the eastern section. The bars indicate rms vertical displacement $(S, T)$ or the rms flow variability.

critical flow is based on an ideal two-layer system, which is only an approximation to the real case. Depending on the way the currents and the thicknesses of both layers are determined, the values of the calculated Froude number $G$ may vary. However, such estimates will indicate the overall magnitude of $G^{2}$ and allow comparison of different states. For the applications below, the current of the two layers $u_{2}$ was determined by taking the mean value away from the main shear zone. For calculations of $G^{2}$ this was used together with the corresponding mean values of the density $\left(\rho_{1}=1027.2 \mathrm{~kg} \mathrm{~m}^{-3}\right.$ and $\rho_{2}=$ $1029.1 \mathrm{~kg} \mathrm{~m}^{-3}$ ) resulting from our CTD measurements.

In the Strait of Gibraltar the interface between Mediterra- nean and Atlantic water is usually defined as an isohaline. In the present work, Froude numbers are computed for both the 37.4 and the 38.1 isohaline as the interface location. As it is discussed in the companion of this paper (BSLC), the 38.1 isohaline seems to be the most appropriate one to use for calculations of the volume transport through the eastern entrance of the strait. The CTD and ADCP measurements of the two research cruises Poseidon 217 and Poseidon 234 can now be used for estimating the tidal and seasonal variations of the hydraulic state as well as the influence of the internal bore.

During cruise Poseidon 217 in April 1996, two time series stations were carried out at the eastern entrance of the strait 


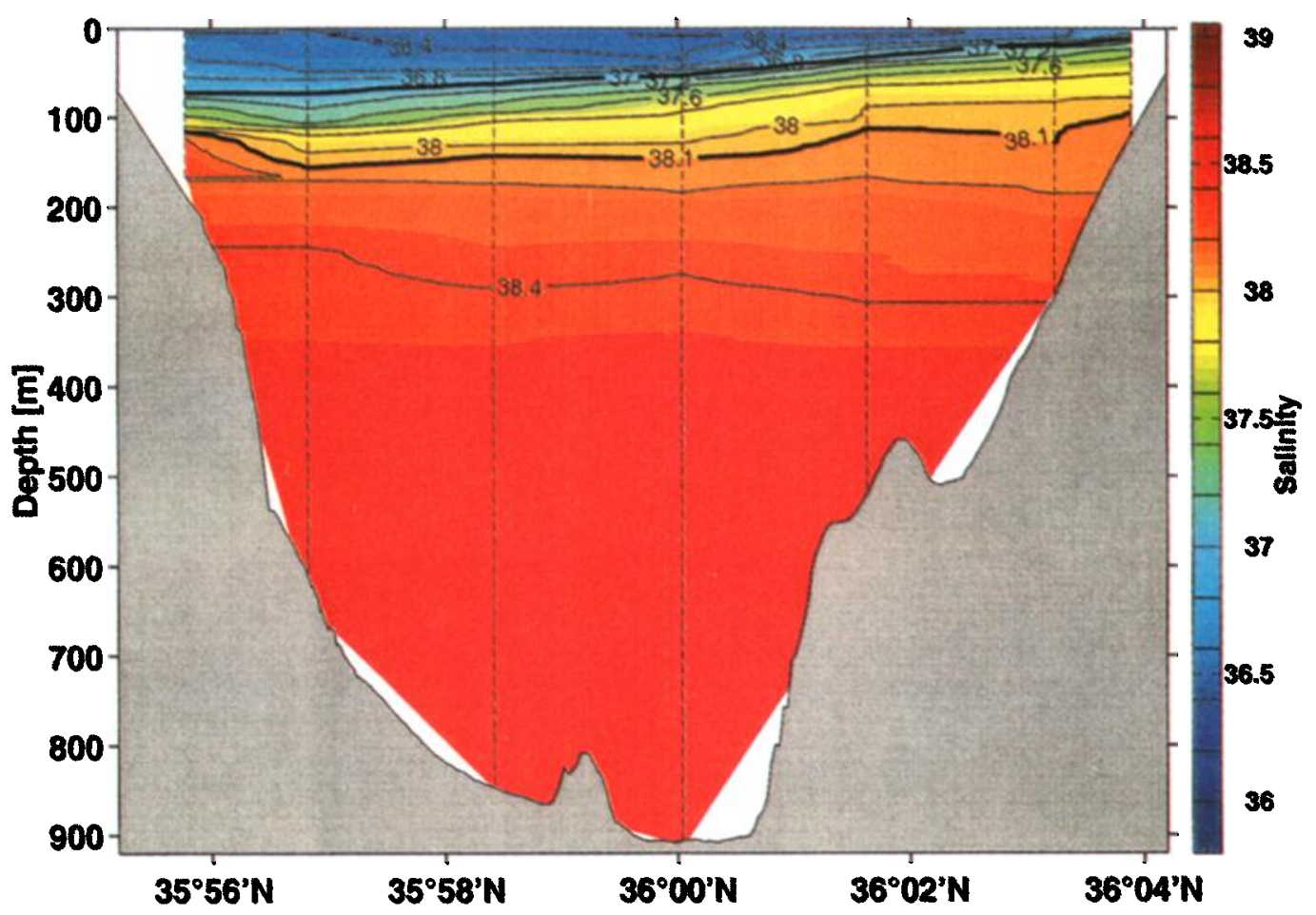

Plate 8. Salinity distribution along the eastern section E, averaged from four nonsynoptic CTD sections during Poseidon 217.

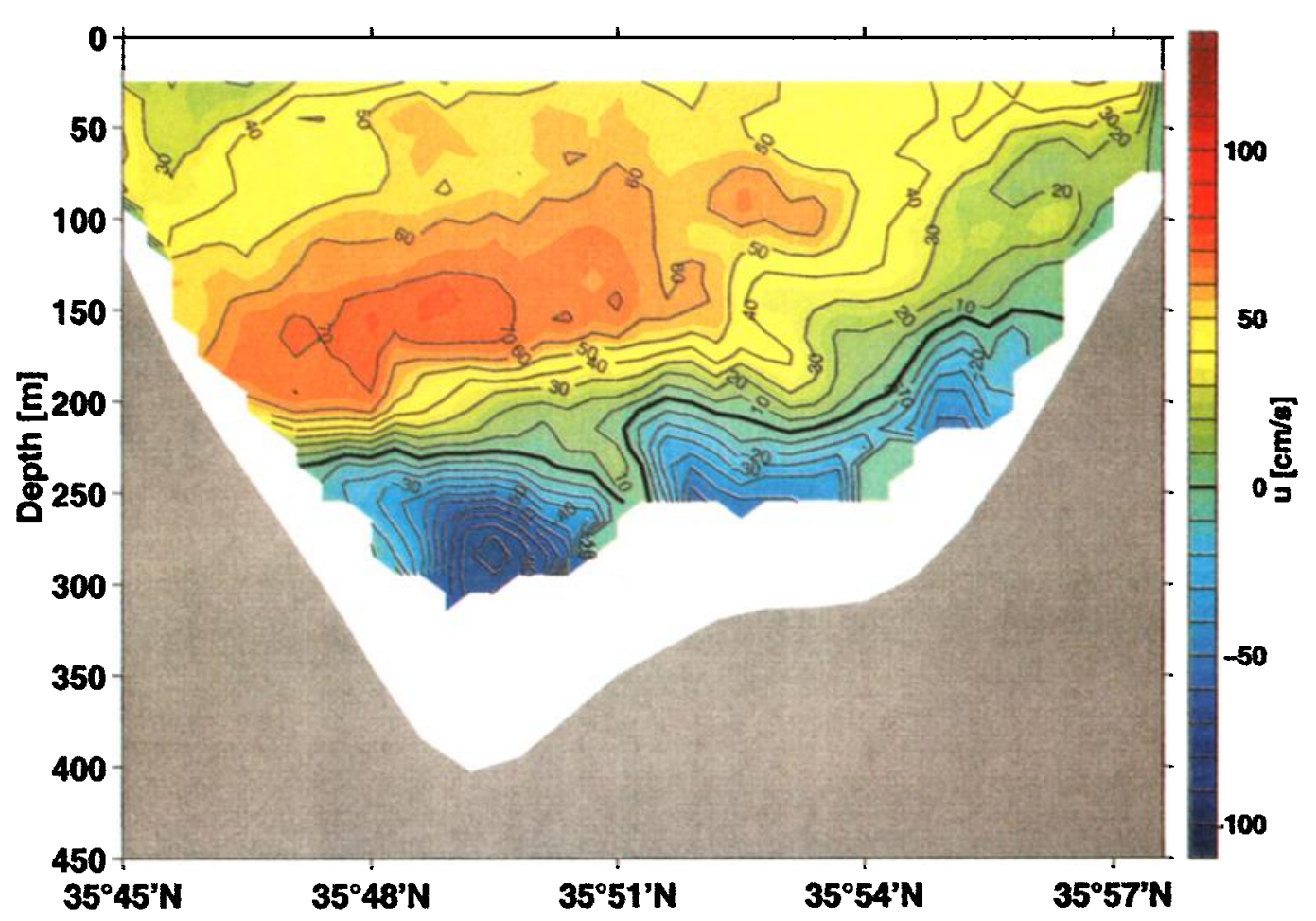

Plate 9. Mean along-strait current $\left(\mathrm{cm}^{-1}\right)$ through the Strait of Gibraltar at the western section $\mathrm{W}$ from vmADCP sections over a tidal period at spring tide (Poseidon 234). 

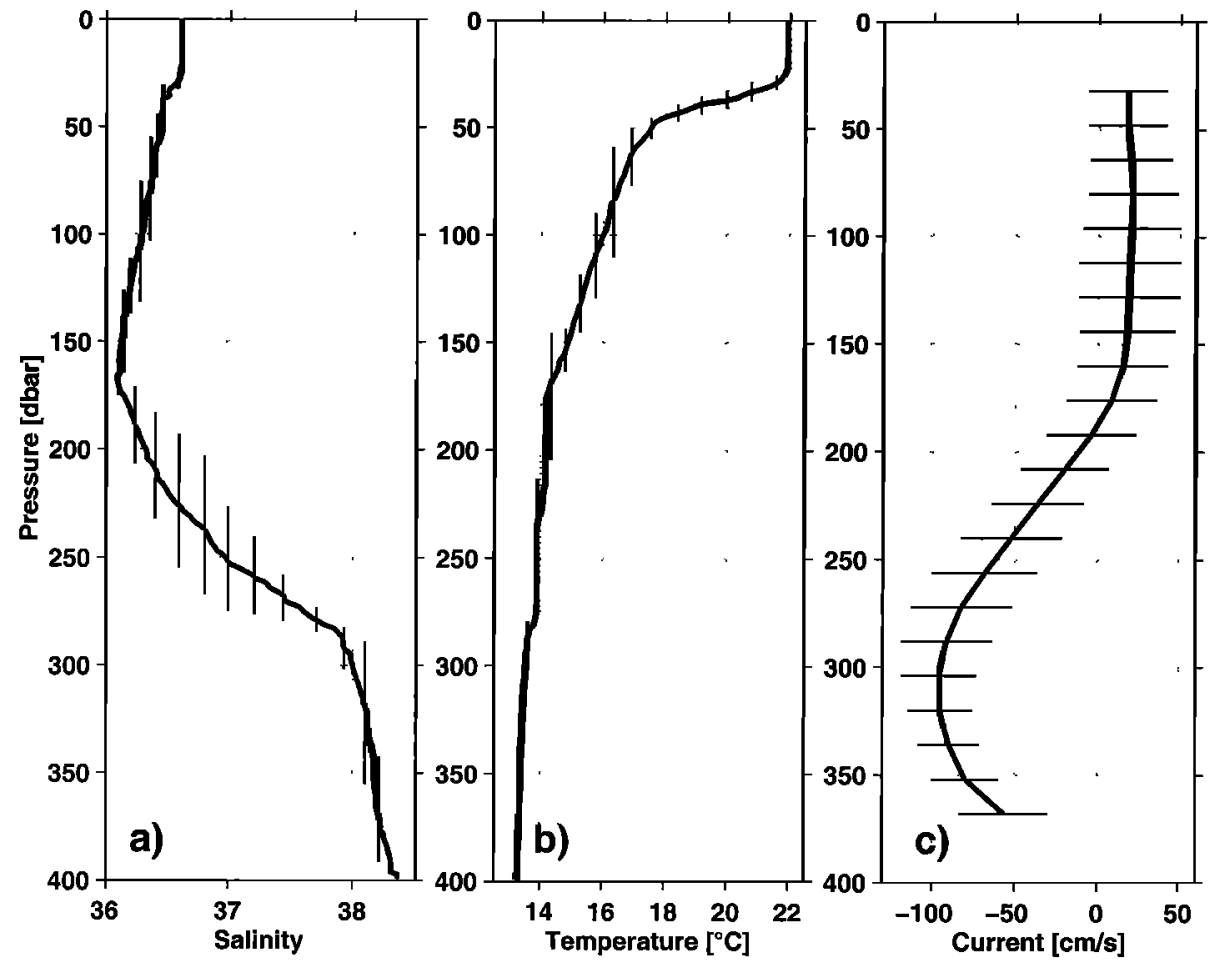

Figure 2. Approximate tidal-mean profiles of (a) salinity, (b) temperature $\left({ }^{\circ} \mathrm{C}\right.$ ), and (c) along-strait current $\left(\mathrm{cm} \mathrm{s}^{-1}\right)$, at the western section W from CTD measurements during Poseidon 234. Vertical/horizontal bars are as in Plate 7.

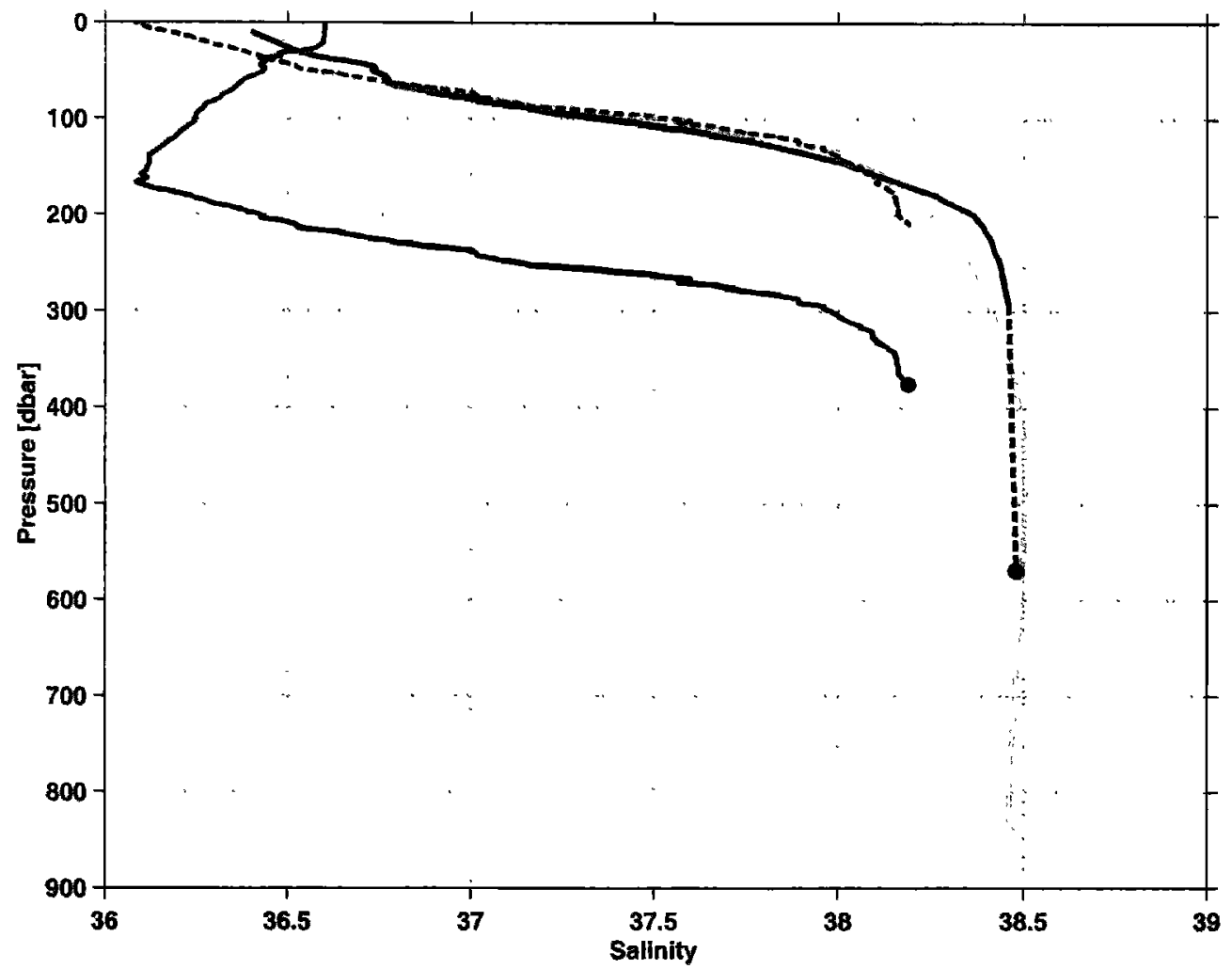

Plate 10. Salinity profiles averaged from time series CTD stations at the eastern section (E, red), near the sill (B1, black), and the western section (W, blue). The red and blue profiles are averaged over a complete tidal cycle and go to the bottom (marked by the dots), and the black one covers only part of a cycle and does not reach the bottom at $550 \mathrm{~m}$ (it is therefore extrapolated to the bottom, dashed line). The similarity of the profiles in the 36.5-38 range is emphasized by plotting the blue profile also displaced vertically (blue dashed). 


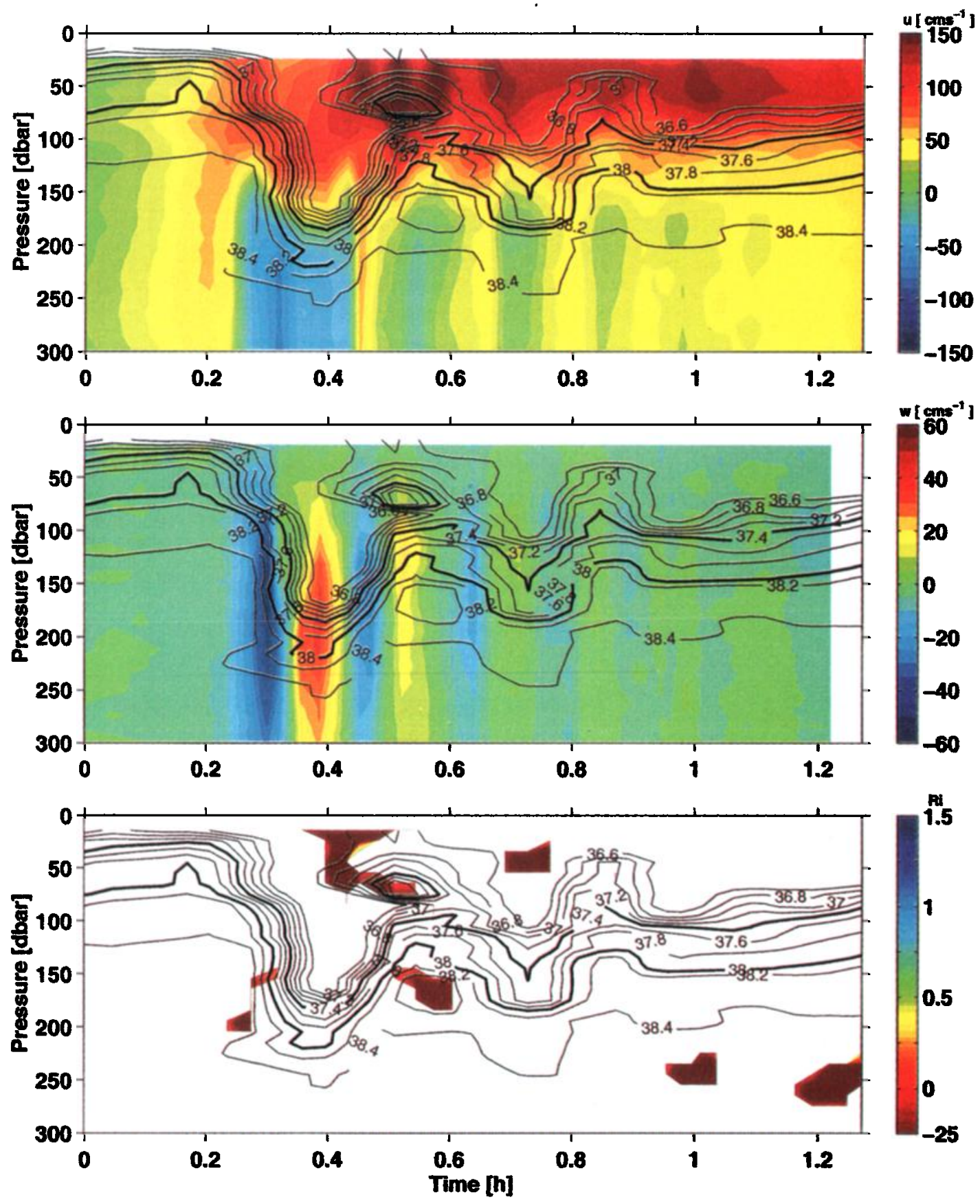

Plate 11. Observation of an internal bore (Poseidon 234) near Camarinal Sill (site B1). The given time is relative to high water in Tarifa. (top) Along-strait current $\left(\mathrm{cm} \mathrm{s}^{-1}\right)(\mathrm{vmADCP}$, colored) and isohalines (CTD, contour lines). Heavy lines are the 37.4 and 38.0 isohalines. (middle) Vertical current $\left(\mathrm{cm} \mathrm{s}^{-1}\right.$ ) (vmADCP, colored) and isohalines (CTD, contour lines). (bottom) Richardson numbers smaller than 1.5 color-coded, emphasizing negative values (unstable regions), and isohalines. Apart from small unstable patches, the values are larger than 1.5 .

over a complete $M_{2}$ tidal cycle; one near spring tide and one during neap tide. The salinity data during the spring tide station were obtained from rapid continuous CTD profiles ("yoyo") to $300 \mathrm{~m}$, yielding the $G^{2}$ estimate in Figure 4, while during the neap tide station, single full-depth CTD profiles were repeated 14 times over the tidal cycle, resulting in the estimates of Figure 5. The mean current of the two layers was determined from the simultaneous vmADCP data in both cases. In October 1997, similar measurements are available during one tidal cycle, using single full-depth CTD casts and vmADCP data again. The corresponding fall estimates for $G^{2}$ are shown in Figure 6.

A comparison of the calculations from the measurements of both research cruises shows that the values of $G^{2}$ are in the vicinity of or above 1 during a part of the tidal cycle in April 1996 (Poseidon 217), while they are significantly smaller in October 1997 (Poseidon 234), reaching maximal values of 0.4 . The highest values of $G^{2}$ do not occur when the internal bore 

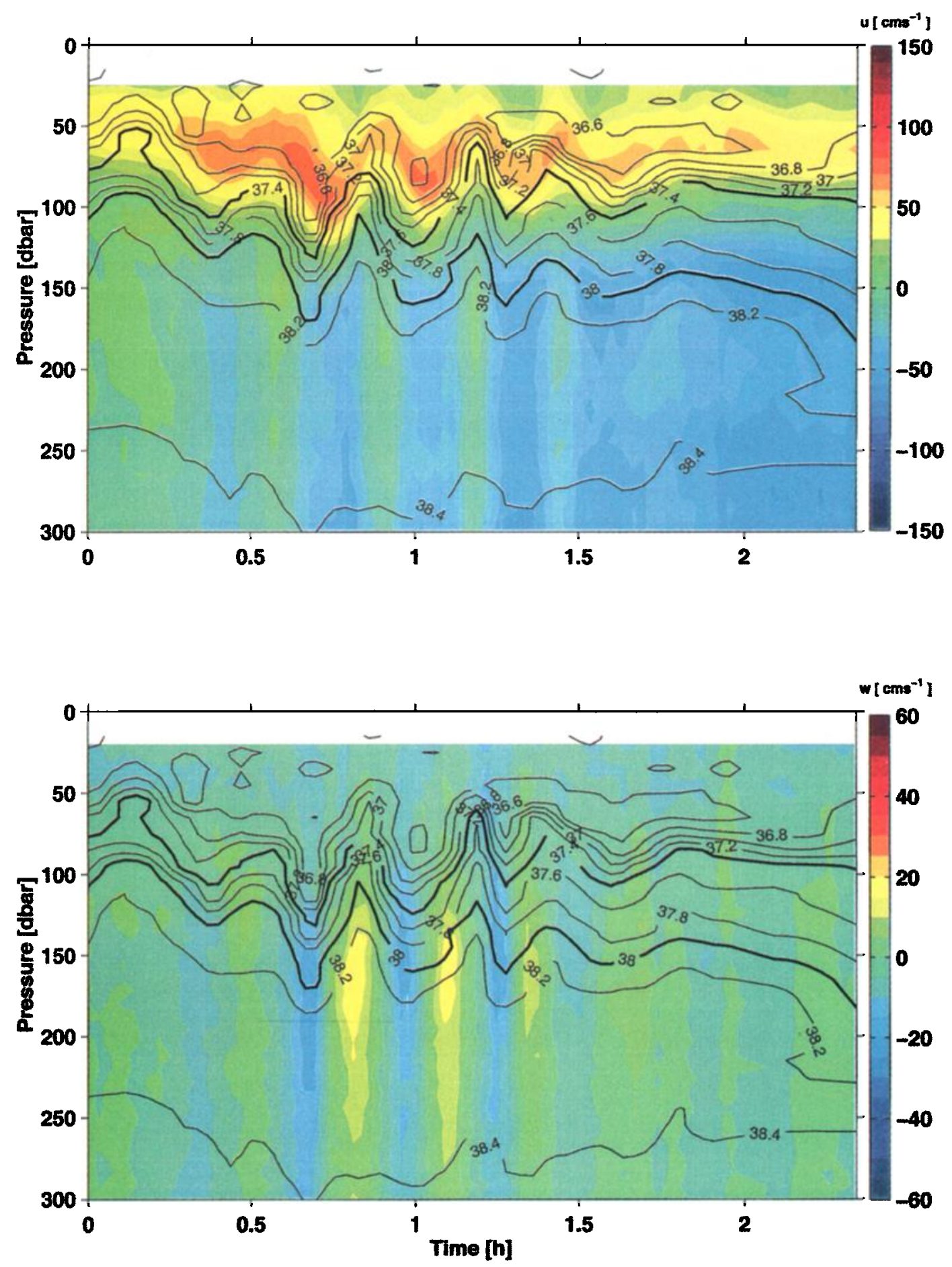

Plate 12. Observation of an internal bore (Poseidon 234) at the eastern entrance of the strait (site B2). The given time is relative to high water at Tarifa. (top) Along-strait component of the current ( $\mathrm{cm} \mathrm{s}^{-1}$ ) (vmADCP, colored) and isohalines (CTD, contour lines). Heavy lines are the 37.4 and 38.0 isohalines. (bottom) Vertical current $\left(\mathrm{cm} \mathrm{s}^{-1}\right)$ (vmADCP, colored) and isohalines (CTD, contour lines).

passes by but a short time before the maximal tidal flow into the Mediterranean Sea is reached in the upper layer. The difference between the spring and neap tide measurements in April is related to the larger upper-layer currents observed in those realizations during neap tides (see also the last two panels in Plate 5, to which the Froude number time series correspond). Longer moored time series (see companion pa- per BSLC) suggest, however, that these changes between spring and neap tides are not significant.

The reason for the more prominent spring-fall differences can be due to seasonal changes in the flow and/or the interface depth. The IADCP measurements of our cruises show that the layer of zero velocity is shallower by $\sim 20-50 \mathrm{~m}$, and the current of the upper layer is larger by $\sim 20 \mathrm{~cm} \mathrm{~s}^{-1}$ in April 1996 

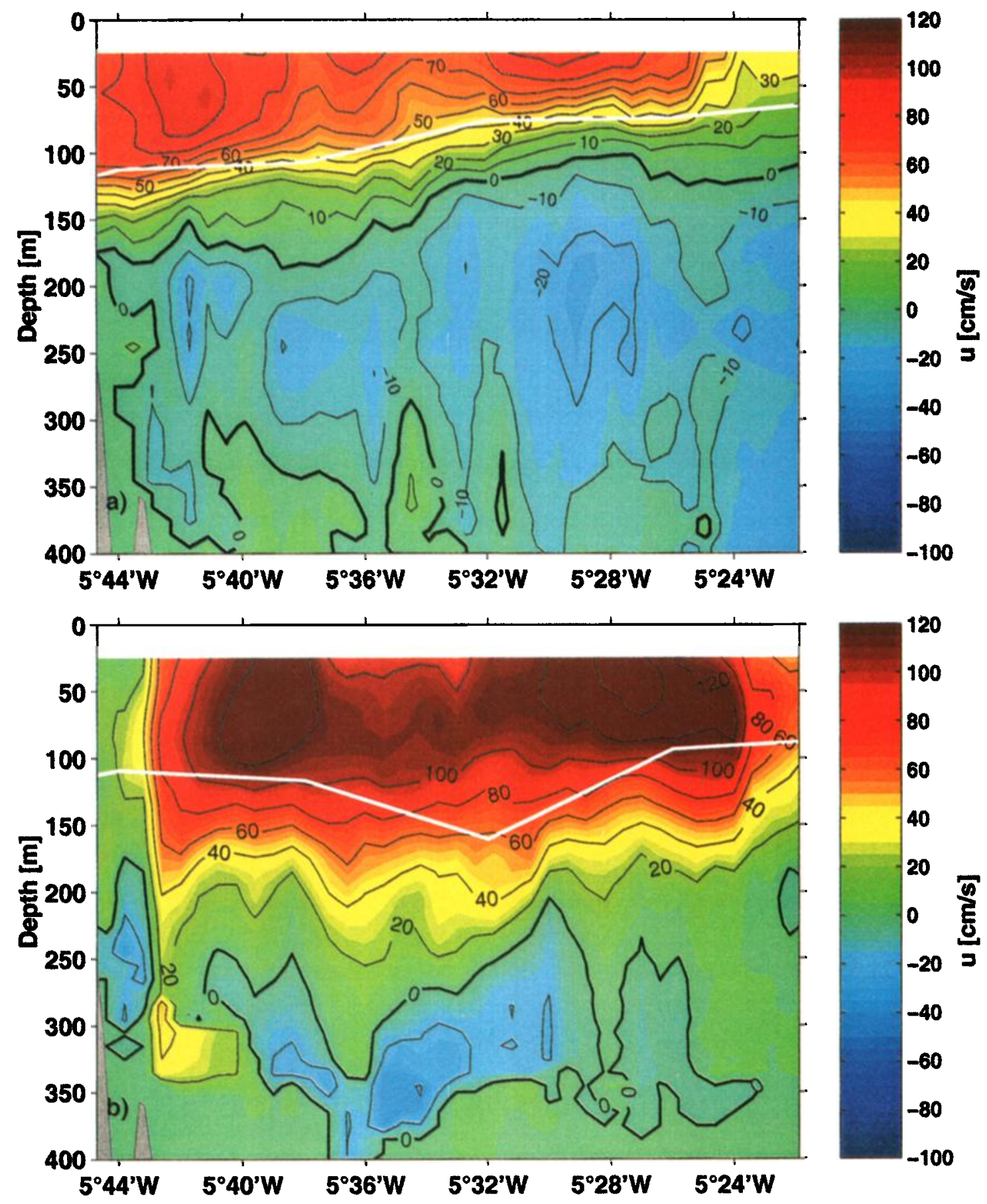

Plate 13. Mean along-strait sections of the along-strait current $\left(\mathrm{cm} \mathrm{s}^{-1}\right)$ from four vmADCP sections during (a) spring and (b) fall. Since these sections must be expected to be aliased by tides, tidally corrected depths for the interface depth are indicated by the white lines (see text).

than in October 1997 (Figure 7a). This is consistent with interface depths derived from the mean CTD profiles of both research cruises (Figure $7 b$ ). These observations suggest that the depth of interface in the east is closely related to maximal or submaximal exchange conditions.

The along-strait sections of the mean current speed with vmADCP support these observations. In the absence of sufficient CTD/XBT data the layer of maximum shear from the vmADCP is taken as a qualitative indication of the position of the interface. Although some of the single sections have shown that this is not always a good measure for the instantaneous interface position (e.g., Plate 5), the mean flow field seems to give a reasonable indication of the tidally averaged interface depth in the middle of the strait (e.g., Plates 4 and 8).

In April 1996 the interface appears to get significantly shallower from Camarinal Sill to the east (Plate 13a), which is consistent with the slope of the interface expected for hydraulically controlled flow (Figure 3). In contrast, the measurements in October 1997 do not show a slope of the layer of maximum shear toward the east (Plate 13b). In order to test 
a)

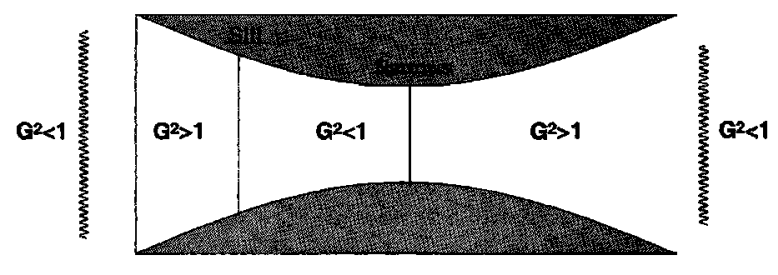

b)

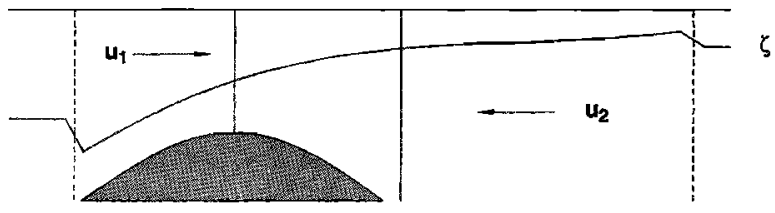

Figure 3. The composite Froude number $G$ for hydraulically controlled flow through a strait with a sill and a contraction. (a) Between the controls, where the flow is subcritical. Outside of that the flow is supercritical. The conditions in the reservoir are matched by hydraulic jumps. (b) Along-strait section with the depth of the interface $\zeta$.

the robustness of this result against temporal aliasing (the interface would have moved with the tidal variations while doing the along-strait section), a tidal fit with the tidal constituents $M_{2}, K_{1}$, and $S_{2}$ of the vertical interface movement was carried out at various locations along the strait, using all the vmADCP data available. This was then used to correct the interface depths from Plates 13a and 13b (shown there as white lines). The result does not change qualitatively.

The various observations above all are consistent with the hypothesis that the flow is hydraulically controlled during part of the tidal cycle in April 1996 and not in October 1997. However, these results are based on only a few tidal cycles of measurements, and it is also possible (if the regime shifted laterally) that the fall measurements were located east of the

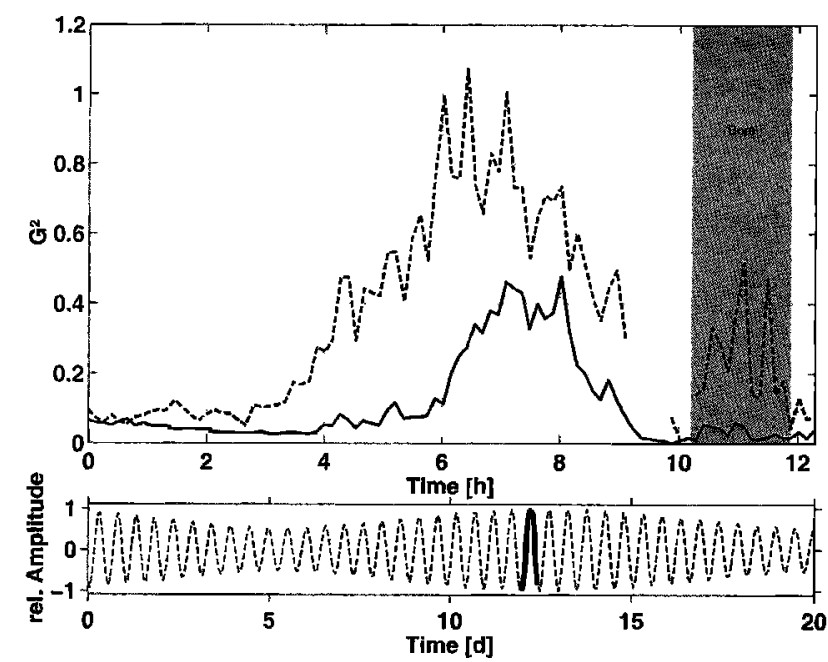

Figure 4. (top) The composite Froude number $G^{2}$ for the 38.0 isohaline (solid line) and for the 37.4 isohaline (dashed line) for a time station with CTD-yoyo and vmADCP at site $d$ on the eastern section during spring tide in spring 1996 (Poseidon 217). The time during which the internal bore was observed is marked in grey. (bottom) Timing of the measurements within a spring neap tidal cycle of the currents in 50-m depth.

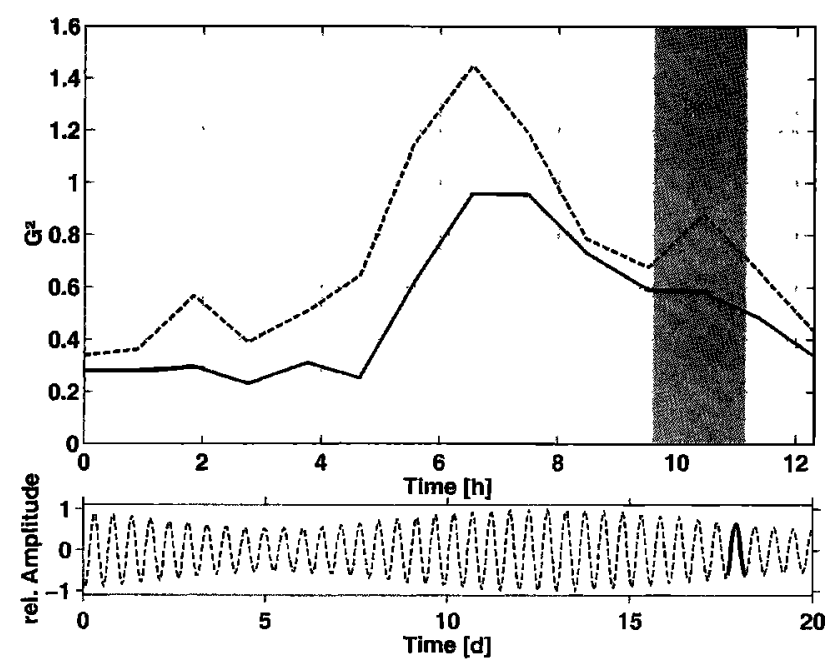

Figure 5. Similar to Figure 4, but during neap tide and using slower CTD casts with vmADCP data.

area of supercritical flow, so that no Froude numbers $G^{2}>1$ could be measured. Nonetheless, our observations seem to confirm the results from Garrett et al. [1990], who showed that the exchange through the Strait of Gibraltar has the tendency to be maximal (hydraulically controlled) in the first half of the year and submaximal in summer and fall. They also found slopes of the interface for October and April which are in good agreement with the observations presented here.

\section{Summary}

Intensive shipboard observations from two cruises in the Strait of Gibraltar were presented, including various modes of CTD, IADCP, and vmADCP measurements, in order to capture the distributions and rapid changes of the flow and stratification over tidal cycles. These represent new views of the joint spatiotemporal structures of the flow and stratification fields. The purpose of the effort was to gather as much spatial information as possible, for later merging with temporal infor-

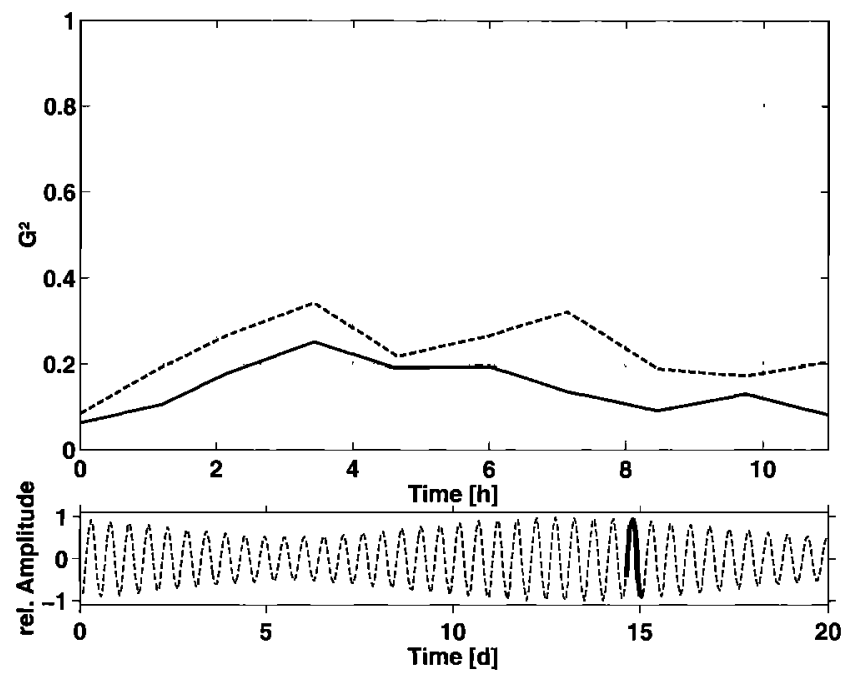

Figure 6. Similar to Figure 5 but for observations during fall 1997 (Poseidon 234). 


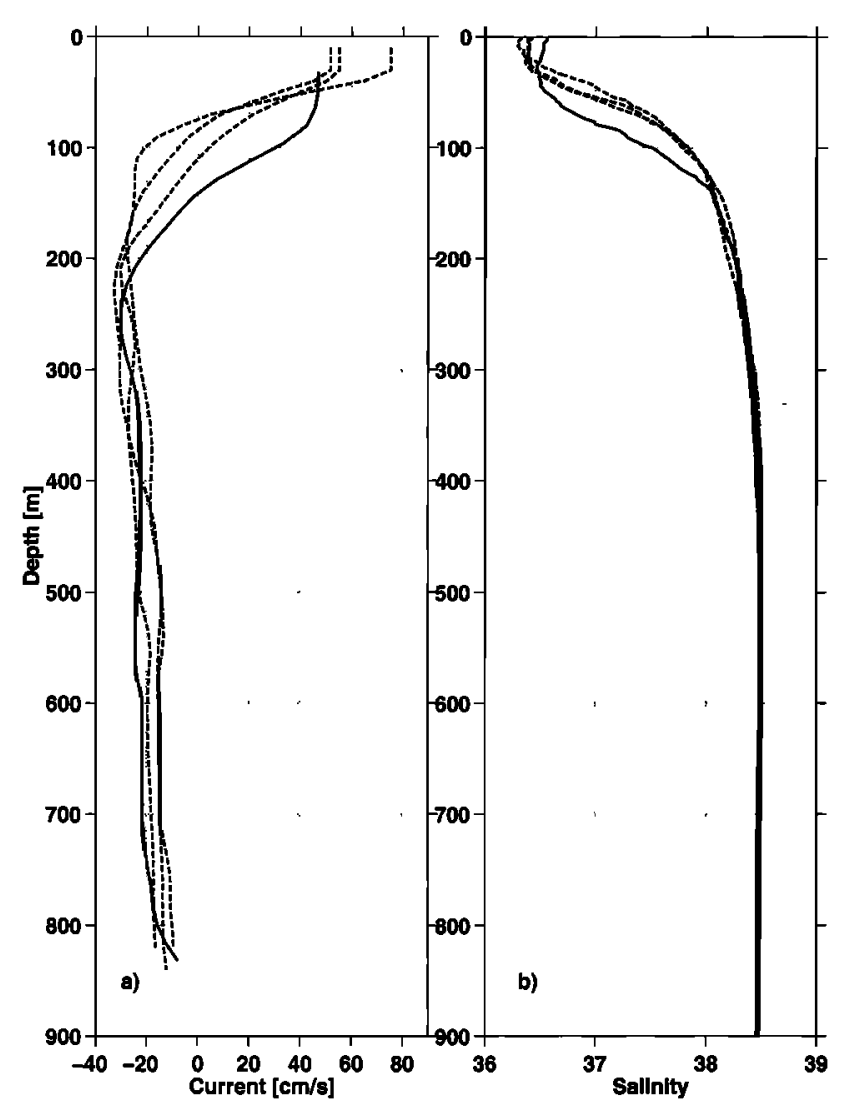

Figure 7. (a) Mean along-strait current profiles from IADCP time stations over $M_{2}$ tidal cycles at the center of the eastern entrance of the strait (site d). Three realizations from Poseidon 217 (April 1996) are plotted dashed, and one is plotted from Poseidon 234 (October 1997) in solid. (b) Mean salinity profiles from CTD measurements during the same time stations.

mation from moored data at specific locations (this is presented in the companion paper BSLC).

Apart from several along-strait sections, the measurements concentrated on repeated rapid crossings and time stations at three sections in the strait, marked $E, S$, and $W$ in the map of Figure 1. The data from Camarinal Sill, where most prior moored experiments took place, revealed large changes in the flow field over tidal cycles, with resolved vertical and horizontal shears up to 0.041 and $1.610 \mathrm{~m}^{-3} \mathrm{~s}^{-1}$, respectively.

While the interface movement causes order- 1 effects in mass and property transports at the sill, this is much reduced at the eastern section $\mathrm{E}$ in the strait. Here it is expected that interface movement would not need to be monitored for quantifying transports. Tidal flows are somewhat weaker than those at the sill, but vertical and horizontal shears have a similar order of magnitude. The tidal-mean flow section has its zero crossing significantly below the interface (if the latter is defined in terms of highest water mass and flow gradients). The time stations show significant changes in the structure of the salinity interface layer over tidal cycles. The flow shear qualitatively tracks the salinity interface, but the maxima are frequently found at different depths. Tidal-mean profiles of $T, S$, and flow are derived together with measurements of the excursions due to tides at various depths.

A comparison of the flow and water mass structure after the outflow has passed the sills is obtained from data along section
W. The Mediterranean layer has descended following the bathymetry but approximately maintained its thickness. Tidal excursions are reduced. The main difference at this section is a change in water mass properties of the Mediterranean outflow due to the mixing it has experienced in the strait since it entered the eastern section. In particular, the mean salinity of what one might identify as the core of the outflow has decreased from 38.43 to 38.17 .

The stratification changes and horizontal and vertical flows associated with the internal bore were recorded at several places with high-resolution profiles. Apart from the extreme temporal changes in all variables, new observations are presented on the vertical velocities and on unstably stratified patches of water, which apparently became detached from the interface as a result of turbulent overturning.

Time series of the composite Froude number could be estimated for the first time from joint vmADCP and CTD measurements at the eastern entrance of the strait in spring (spring and neap tides) and in fall. These estimates, as well as qualitative interface tilts from the flow structure observed in alongstrait sections, are consistent with hydraulically controlled and maximal exchange in April 1996. Corresponding conditions were not observed in October 1997, the interface being lower and with typical surface flows of smaller amplitudes.

Acknowledgments. This work was funded through the EU project CANIGO (MAS3-CT96-60). We thank the captain and crew of R/V Poseidon for their help during both research cruises in the Strait of Gibraltar.

\section{References}

Armi, L., and D. M. Farmer, Maximal two-layer exchange through a contraction with barotropic net flow, J. Fluid Mech., 164, 27-51, 1986.

Armi, L., and D. M. Farmer, The flow of Mediterranean water through the Strait of Gibraltar, Prog. Oceanogr., 21, 1-105, 1988.

Baschek, B., U. Send, J. G. Lafuente, and J. Candela, Transport estimates in the Strait of Gibraltar with a tidal inverse model, J. Geophys. Res., this issue.

Bray, N. A., J. Ochoa, and T. H. Kinder, The role of the interface in exchange through the Strait of Gibraltar, J. Geophys. Res., 100, 10,755-10,776, 1995.

Bryden, H., et al., Exchange through the Strait of Gibraltar, Prog. Oceanogr., 33, 201-248, 1994.

Candela, J., The Gibraltar Strait and its role in the dynamics of the Mediterranean Sea, Dyn. Atmos. Ocean, 15, 276-299, 1991.

Farmer, D. M., and L. Armi, Maximal two-layer exchange over a sill and through a combination of a sill and a contraction with barotropic flow, J. Fluid Mech., 164, 53-76, 1986.

Farmer, D. M., and L. Armi, The flow of Atlantic Water through the Strait of Gibraltar, Prog. Oceanogr., 21, 1-105, 1988.

Garrett, C., M. Bormans, and K. Thompson, Is the exchange through the Strait of Gibraltar maximal or submaximal? in The Physical Oceanography of Sea Straits, edited by L. J. Pratt, pp. 271-294, Kluwer Acad., Norwell, Mass., 1990.

Price, J. F., M. O'Neil Baringer, R. G. Lueck, G. C. Johnson, I. Ambar, G. Parrilla, A. Cantos, M. A. Kennelly, and T. B. Sanford, Mediterranean outflow mixing and dynamics, Science, 259, 1277-1282, 1993. Schuler, M., Die Störung von Pendel- und Kreiselapparaten, Phys. $Z$., $X X I V, 244-350,1923$.

Send, U., P. F. Worcester, B. D. Cornuelle, C. O. Tiemann, and B. Baschek, Integral measurements of mass transport and heat content in straits from acoustic transmissions, Deep Sea Res., in press, 2001.

B. Baschek, Institute of Ocean Sciences, P.O. Box 6000, Sidney, British Columbia, Canada V8L 4B2. (burkard@uvic.ca).

U. Send, Institut für Meereskunde, Düsternbrooker Weg 20, 24105 Kiel, Germany. (usend@ifm.uni-kiel.de).

(Received May 24, 2000; revised July 13, 2001; accepted July 24, 2001.) 